\title{
A Importância da Suspeição Clínica no Diagnóstico e Tratamento do Câncer Colorretal Hereditário
}

\author{
The Importance of Clinical Suspicion on the Diagnosis and \\ Treatment of Hereditary Colorectal Cancer
}

\author{
${ }^{1}$ MARCUS VALADÃO; ${ }^{2}$ GUILHERME GRAZIOSI; ${ }^{1}$ MARCIO CARNEIRO; ${ }^{1}$ RICARDOARY LEAL; \\ ${ }^{3}$ ANTONIO ABÍLIO P. SANTA ROSA $;{ }^{2}$ RICARDO ALMEIDA; $;{ }^{4}$ ROBERTO JAMIL MUHARRE \\ ${ }^{I}$ Staff da II Clínica Cirúrgica do Hospital Geral de Bonsucesso , HGB, Rio de Janeiro, RJ; \\ ${ }^{2}$ Residente da II Clínica Cirúrgica do Hospital Geral de Bonsucesso, HGB, Rio de Janeiro, RJ; ${ }^{3}$ Geneticista Clínico do \\ Hospital Geral de Bonsucesso, HGB, Rio de Janeiro, RJ; ${ }^{4}$ Chefe da II Clínica Cirúrgica do Hospital Geral de \\ Bonsucesso, HGB, Rio de Janeiro, RJ.
}

\begin{abstract}
VALADÃO M; GRAZIOSI G; CARNEIRO M; LEAL RA; ROSA AAPS; ALMEIDA R; MUHARRE RJ. A Importância da Suspeição Clínica no Diagnóstico e Tratamento do Câncer Colorretal Hereditário. Rev bras Coloproct, 2008;28(4): 454-461.

RESUMO: Neste trabalho relatamos o caso de um paciente portador de síndrome de Lynch (HNPCC) que desenvolveu câncer retal metacrônico em curto intervalo de tempo após tratamento do tumor primário (câncer de cólon direito). $O$ objetivo deste relato de caso é salientar a importância da suspeição clínica no diagnóstico de câncer colorretal hereditário e suas implicações terapêuticas.
\end{abstract}

Descritores: Câncer colorretal hereditário; diagnóstico; tratamento.

\section{INTRODUÇÃO}

Neoplasia maligna mais comum do tubo digestivo, o câncer colorretal (CCR) teve sua incidência aumentada nos últimos anos, principalmente em áreas consideradas de baixo risco (países em desenvolvimento). Aproximadamente $80 \%$ dos pacientes desenvolvem o câncer colorretal (CCR) de forma esporádica, enquanto que em $20 \%$ há uma suscetibilidade hereditária à neoplasia. Estima-se em cerca de meio milhão o número de óbitos por esta doença a cada ano, com tendência a queda na mortalidade nos últimos anos ${ }^{1}$. No Brasil, o CCR é a quinta neoplasia maligna mais diagnosticada (ocupando segundo lugar na região Sudeste) e a quarta causa de morte por câncer ${ }^{2-3}$. São condições hereditárias freqüentemente associadas a CCR: a polipose adenomatosa familiar (PAF) e o cân-

$\overline{\text { Trabalho realiza }}$ do no Hospital Geral de Bonsucesso - Rio de Janeiro. cer colorretal hereditário não polipose (HNPCC), também denominada síndrome de Lynch ${ }^{4-5}$.

Das formas hereditárias, o câncer colo-retal hereditário não polipose (HNPCC) é a mais comum, sendo responsável por 20 - 30\% destes, o que equivale a $3 \%$ a $5 \%$ de todas as neoplasias colorretais ${ }^{1}$. Classicamente como é conhecida, a síndrome de Lynch I e II é uma doença autossômica dominante sendo cinco vezes mais frequiente que a polipose adenomatosa familiar $(\mathrm{PAF})^{2}$ e é decorrente de mutações em genes responsáveis pelo reparo do DNA. O envolvimento colônico isolado ocorre na síndrome Lynch I, enquanto no subtipo II ocorre câncer colorretal associado a neoplasias em outros órgãos, como de endométrio, ovário, mama, estômago, intestino delgado,sistema hepatobiliar, pâncreas, ureter e de pelve renal ${ }^{3}$. A penetrância está em torno de $80 \%{ }^{4,6}$, ou seja, indivídu- 
os que herdam esta mutação têm uma chance de aproximadamente $80 \%$ de desenvolvimento de CCR.

Em HNPCC, as neoplasias tendem a ocorrer preferencialmente no cólon direito (60-70\% ocorrem proximalmente à flexura esplênica), mais precocemente (por volta dos 45 anos de idade), têm taxa aumentada de tumores metacrônicos e sincrônicos (20\%), ao contrário do que ocorre na forma esporádica, as quais são diagnosticadas em pacientes com média de 65 anos e predominam no cólon esquerdo. Ainda, no HNPCC há uma proporção aumentada de tumores mucinosos e de grau de diferenciação mais alto, bem como infiltração linfática da margem tumoral ${ }^{7-9}$, entretanto, a sobrevida é comparativamente melhor com relação aos casos esporádicos, em parte devido à apresentação tumoral menos avançada e, mesmo comparações estádio a estádio, demonstraram vantagem de sobrevida em HNPCC sobre pacientes com câncer colo-retal esporádico no estádio III. ${ }^{10}$

Em decorrência da ausência de sinais clínicos capazes de predizer a suscetibilidade a HNPCC, a história familiar tem sido o método principal em identificar pacientes de risco. De modo a identificar tais famílias, em 1990, o Grupo Colaborativo Internacional (ICG) em HNPCC criou os critérios de Amsterdam ${ }^{9}$, objeto de revisão posterior por serem demasiado restritivos ao excluir membros da família que apresentassem tumores extracolônicos. Esses critérios foram expandidos, dando origem aos critérios de Amsterdam II em contraposição aos originais (denominados a partir de então, Amsterdam I), passando a considerar as outras neoplasias como parte integrante do espectro de HNPCC. Ambos os critérios são apresentados abaixo.

Critérios de Amsterdam I (1990) ${ }^{9}$

Pelo menos três parentes afetados;

Um paciente acometido deve ser parente de primeiro grau dos outros dois;

Duas ou mais gerações acometidas;

Pelo menos um dos parentes acometidos com diagnóstico de CCR antes dos 50 anos;

Exclusão de PAF;

Tumores examinados histologicamente.

Critérios de Amsterdam II ${ }^{11}$

Identificação clínica do HNPCC requer três ou mais parentes com neoplasia associada a HNPCC (CCR ou câncer de endométrio, intestino delgado, ureter ou pelve renal) mais o seguinte:

Pelo menos três ou mais familiares com neoplasias associadas à HNPCC (CCR ou câncer de endométrio, intestino delgado, ureter ou pelve renal);
Um paciente acometido deve ser parente de primeiro grau dos outros dois;

Duas ou mais gerações acometidas;

Pelo menos um indivíduo afetado diagnosticado antes de 50 anos;

CCR;

Exclusão de PAF em quaisquer casos de

Tumores examinados histologicamente.

Apesar do crescente conhecimento das bases genéticas de HNPCC, ainda não está completamente estabelecido um algoritmo para testagem genética em pacientes de risco. Muitos autores advogam que o teste inicial para identificação desta síndrome seria a pesquisa de instabilidade de microssatélites (Microsatellite instabilility - MSI). A análise é realizada em um painel de cinco marcadores já padronizados. A MSI é pesquisada pela comparação de seqüências de microssatélites das células tumorais com as do tecido normal, sendo classificada de acordo com o número de marcadores onde for detectada instabilidade, em MSS (stable) quando nenhum marcador mostra instabilidade, MSI-L (low) quando se observa instabilidade em um marcador, e MSI-H (high) quando houver instabilidade em dois ou mais marcadores. Variabilidade entre estes dois clones celulares indica MSI ${ }^{12}$. Diante disso, o Instituto Nacional de Câncer americano (NCI) desenvolveu os critérios de Bethesda durante a conferência de consenso realizada em 1997. Esse consenso sugere que pacientes que apresentem estes critérios devam ser submetidos à pesquisa de instabilidade de microssatélites para o diagnostico de HNPCC. Bastante usados atualmente, estes critérios foram submetidos à recente revisão de forma a aprimorar a identificação das famílias em risco. Ambos seguem abaixo:

Critérios de Bethesda (1997) ${ }^{13}$ térios de Amsterdam;

CCR em famílias que preenchem os cri-

Dois tumores relacionados à HNPCC, incluindo CCR sincrônico ou metacrônico, ou associado com neoplasias extracolônicas (endométrio, ovário, gástrico, hepatobiliar, de intestino delgado ou carcinoma de células transicionais de ureter ou pelve renal);

CCR e um parente de primeiro grau com CCR e/ou neoplasias extra-colônicas associadas a HNPCC, e/ou adenoma colorretal, sendo pelo menos um dos cânceres diagnosticado antes dos 50 anos e o adenoma diagnosticado antes dos 40 anos; 
Rev bras Coloproct Outubro/Dezembro, 2008
A Importância da Suspeição Clínica no Diagnóstico e

Tratamento do Câncer Colorretal Hereditário

Marcus Valadão e Cols.
Vol. 28
CCR ou carcinoma de endométrio em idade inferior a 45 anos;

CCR localizado em cólon direito com um padrão indiferenciado (sólido, cribiforme) ao exame histopatológico em idade inferior a 45 anos;

CCR com células em anel de sinete em idade inferior a 45 anos; 40 anos.

Adenoma colorretal em idade inferior a

Critérios de Bethesda revisados ${ }^{14}$

- CCR diagnosticado em idade inferior a 50

anos

Presença de tumores colorretais sincrônicos, metacrônicos ou outras neoplasias extracolônicas associadas a HNPCC diagnosticadas em qualquer idade;

CCR com MSI-H diagnosticado antes dos

60 anos;

CCR em indivíduos com um ou mais parentes de primeiro grau acometidos por neoplasias associadas a HNPCC, sendo uma destas diagnosticada antes dos 50 anos;

CCR em indivíduos com dois ou mais parentes de primeiro grau acometidos por neoplasias associadas a HNPCC independentemente da idade

Apesar da inexistência de consenso na literatura a respeito do algoritmo mais indicado a ser utilizado no rastreamento do HNPCC, há uma tendência a se seguirem algumas etapas na identificação dos portadores da síndrome. O primeiro passo seria a utilização dos critérios clínicos descritos acima para identificar as famílias suspeitas, sendo os de Bethesda os mais amplamente utilizados. A partir daí, os indivíduos identificados seriam submetidos à pesquisa de instabilidade de microssatélites e imuno-histoquímica no tecido tumoral, de forma a identificar as proteínas ausentes e inferir, desse modo, o gene mutado. O terceiro passo (padrão-ouro) seria a realização do seqüenciamento genético $^{15}$.

O planejamento do tratamento é baseado na divisão dos pacientes em 3 grupos: 1)Pacientes com diagnóstico de HNPCC confirmado que apresentam câncer colorretal; 2)Pacientes com HNPCC confirmado, mas sem câncer e 3)Pacientes de risco para HNPCC, mas que não têm condições de realizar a testagem genética. $\mathrm{O}$ primeiro grupo (pacientes com CCR e diagnóstico confirmado de HNPCC) deve ser tratado por colectomia total com anastomose íleo-retal ${ }^{16}$ devido à alta incidência de CCR metacrônico (mais de
40\% em 10 anos). Estes pacientes devem ser acompanhados com exame endoscópico do coto retal remanescente, devido ao risco aumentado de câncer. Nos casos raros onde houver tumor retal sem associação com tumor colônico pode ser realizado proctocolectomia total com anastomose íleo-anal com bolsa ileal em "J".

No segundo grupo (pacientes sabidamente portadores de mutação em genes de reparo e que ainda não desenvolveram câncer), existe controvérsia quanto à realização de colectomia total profilática com anastomose íleo-retal, haja visto que HNPCC é uma condição de penetrância elevada $(80 \%)$, mas não completa $^{15-17}$. Este pormenor abre a possibilidade de que, ao se utilizar tal critério para definir intervenções cirúrgicas, pacientes portadores de mutações nos genes de reparo e que tenham uma chance de $20 \%$ de nunca virem a desenvolver CCR sejam submetidos a cirurgias de grande porte desnecessariamente ${ }^{18-20}$. Há uma tendência mundial em não se realizar cirurgia profilática, sendo a conduta mais aceita o seguimento rigoroso com colonoscopia anual ou bianual, iniciando-se aos 25 anos, além de endoscopia digestiva alta e exames de imagem abdominal e pélvica. Para pacientes após a menopausa ou com prole completa, a profilaxia cirúrgica através de histerectomia total abdominal com salpingoooforectomia bilateral pode ser oferecida, sem haver, no entanto, evidências científicas estabelecidas de sua eficácia. ${ }^{21,22}$

Para o terceiro grupo (pacientes sem câncer que desconhecem seu status de portador de mutações em genes de reparo e sem previsão de virem a se submeter à testagem genética em curto prazo), não deve ser indicado cirurgias profiláticas, e sim seguimento rigoroso com exames periódicos, da mesma forma devendo todos eles serem considerados como potenciais portadores de HNPCC até prova em contrário.

Este artigo se propõe a ressaltar a importância da suspeita clínica no diagnóstico de HNPCC e suas implicações no manejo terapêutico desses pacientes, a partir de um relato de caso de um paciente com câncer colorretal tratado no nosso serviço.

\section{RELATO DO CASO}

Paciente E.M.S., sexo masculino, branco, 40 anos, natural de São Pedro da Aldeia (RJ), casado. O quadro clínico iniciou-se com dor abdominal em região hipogástrica, inicialmente em dias alternados, que pio- 
rava após ingestão de certos alimentos. Nos seis meses seguintes, a dor passou a ser contínua, em pontada, de grande intensidade e estendendo-se também para fossa ilíaca direita. Relatava mudança de hábito intestinal com o surgimento de constipação. Negava melena, náuseas ou vômitos. Houve ainda crescimento de tumoração em topografia de fossa ilíaca direita, anorexia e perda de peso de cerca de $8 \mathrm{~kg}$ no período.

Nos antecedentes pessoais, negava passados cirúrgicos ou de internações. Referia história de tabagismo, tendo fumado dois a três maços por dia por 15 anos e parado havia oito. Etilismo social. Sem comorbidades.

Na história familiar observa-se pai falecido de câncer colônico aos 43 anos de idade, mãe viva sem históricos patológicos. Possui quatorze irmãos, sendo doze vivos e dois falecidos, um deles por CCR e outro de causa indeterminada. Segue abaixo o heredograma (Figura 1).

Ao exame físico, apresentava-se em estado geral regular, emagrecido e hipocorado. Ausculta cardiovascular normal. Ausculta pulmonar normal, com murmúrio vesicular universalmente audível, sem ruídos adventícios. Abdome plano, flácido, normotenso, timpânico, indolor à palpação superficial e doloroso à palpação profunda em fossa ilíaca direita, onde se palpava uma massa.
O exame proctológico revelava inspeção normal e palpação sem anormalidades. Ao toque retal, esfíncter normotônico, sem evidências de lesões. Dentre os exames complementares de imagem realizados, a TC de abdômen demonstrou massa em topografia de cólon ascendente, sem ascite ou sinais de carcinomatose. A colonoscopia revelou lesão vegetante de aspecto neoplásico em cólon ascendente, impedindo a progressão do aparelho, cuja biópsia demonstrou adenocarcinoma moderadamente diferenciado, e demais segmentos do cólon sem alterações.

Em agosto de 2006, foi realizada hemicolectomia direita videolaparoscópica com anastomose por grampeador circular número 28 , evidenciando na cirurgia tumor de cólon ascendente e ceco aderido à parede abdominal em goteira parieto-cólica, com linfonodos aumentados em território da artéria cólica direita, porém sem implantes hepáticos ou peritoneais. O exame anatomopatológico revelou tratar-se de adenocarcinoma moderadamente diferenciado localizado no ceco, medindo 3,0 × 6,0 cm, ulcero-infiltrativo, invadindo até a subserosa. Havia ainda metástases para seis linfonodos pericólicos dentre os quinze isolados. A mucosa intestinal adjacente não apresentava alterações histológicas significativas. As margens eram livres de neoplasia. $\mathrm{O}$ estadiamento TNM para o tumor de ceco, portanto, foi pT3 N2 M0 G2 (estadio IIIC).

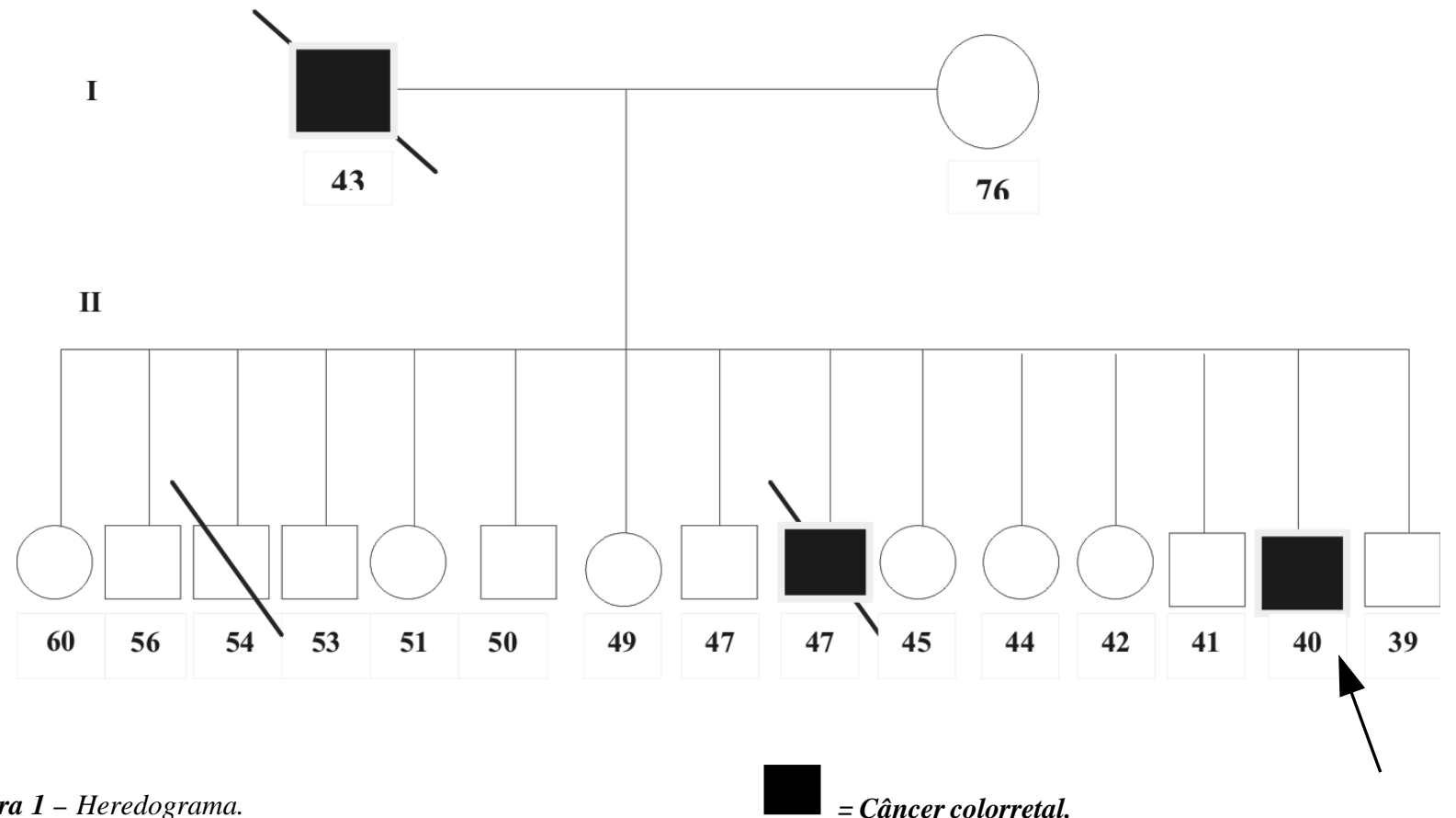

Figura 1 - Heredograma. 
Realizou quimioterapia adjuvante com 5fluorouracil e leucovorin por seis meses. Após quatro meses do início do tratamento quimioterápico, apresentou quadro de hematoquezia e dor abdominal. Foi reinternado em agosto de 2007 e realizado novos exames. A colonoscopia mostrou lesão ulcerada, circunferencial, situada a $10 \mathrm{~cm}$ da margem anal, cuja biópsia evidenciou adenocarcinoma bem diferenciado. A endoscopia digestiva alta demonstrou gastrite enantematosa leve; A TC de abdômen demonstrou lesão circunferencial de reto, sem evidência de doença metastática. O valor do CEA era de 4,0 (VN: 0 - 3,5). $\mathrm{O}$ paciente foi submetido à radioquimioterapia neoadjuvante com término em dezembro de 2007.

Em janeiro de 2008, o paciente foi submetido a uma nova intervenção cirúrgica, onde se evidenciou tumoração volumosa em reto médio, com invasão de vesículas seminais e bexiga. Decidiu-se por realizar proctocolectomia total associada à exenteração pélvica total (Figura 2) com reconstrução urinária à Bricker, além de confecção de bolsa ileal em "J" e ileostomia de proteção. O paciente teve boa evolução, tendo alta hospitalar no $10^{\circ}$ dia de pós-operatório. O exame anatomopatológico revelou adenocarcinoma de reto moderadamente diferenciado, infiltrando vesículas seminais, além de metástases para dois linfonodos do pólo vascular. O estadiamento TNM para o tumor de reto foi pT4 N2 M0 G2 (estádio IIIC). O paciente encontra-se, atualmente, em vigência de quimioterapia adjuvante utilizando o protocolo Xelox.

\section{DISCUSSÃO}

Segundo dados do Instituto Nacional do Câncer (INCA), a estimativa de incidência de câncer colorretal no Brasil para 2008 é de 27.000 novos ca$\operatorname{sos}^{23}$. Considerando-se que $20 \%$ desses casos de CCR (5.400) correspondam à sua forma hereditária e que $30 \%$ destes sejam de HNPCC, teremos 1.620 portadores diagnosticados este ano. Diante desses dados, fica claro que a presente síndrome é subdiagnosticada no nosso país, pois não é incomum encontrar pacientes apresentando critérios evidentes para o diagnóstico de HNPCC e que tiveram apenas o tratamento para o câncer colorretal, não se investigando a possibilidade da doença nos familiares. As causas desse cenário estão, em grande parte, relacionadas à falta de conhecimento do profissional a respeito dessa entidade, uma vez que o simples questionamento da história familiar é

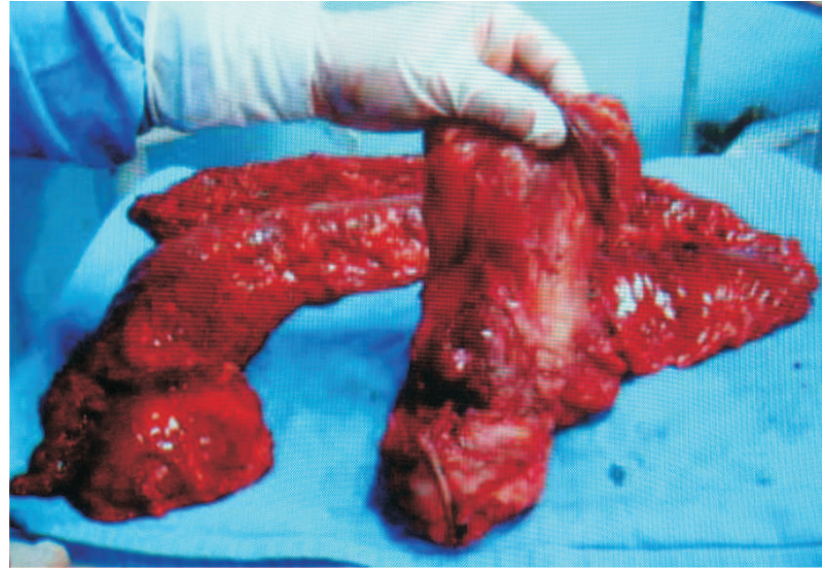

Figura 2 - Espécime cirúrgico constituído por reto, próstata, vesículas seminais, bexiga e todo o cólon remanescente.

capaz de predizer o diagnóstico de HNPCC com acurácia satisfatória ${ }^{13}$. A importância do diagnóstico está não só em oferecer o tratamento mais adequado para esses pacientes, mas também na possibilidade de se prevenir ou diagnosticar de forma precoce a presença do câncer nos familiares, propiciando-lhes os melhores resultados oncológicos.

Aqui cabe salientar que os critérios de Amsterdam I e II foram criados para identificar famílias informativas para estudos de ligação. Os de Bethesda, para identificar famílias onde fosse mais provável a identificação de instabilidade de microssatélites. Nenhum desses critérios é perfeito. Foram criados para fins de pesquisa e não para se excluir famílias de aconselhamento genético e de análise de mutações. Por outro lado, há escolas de pensamento que definem HNPCC simplesmente em termos de presença de mutações nos genes de reparo, posição essa um tanto arriscada ao se considerar que a testagem genética ainda não se constitui em recurso diagnóstico amplamente difundido. ${ }^{12}$

Em decorrência da ausência de sinais clínicos capazes de predizer a suscetibilidade de um dado indivíduo, membro de uma família onde foi diagnosticada HNPCC, em desenvolver câncer, a investigação da história familiar desempenha um papel importante na identificação desses pacientes, bem como das famílias suspeitas. O paciente em questão apresentava critérios clínicos evidentes para o diagnóstico de HNPCC: parente de primeiro grau acometido de câncer colorretal; duas gerações sucessivamente acometidas; pelo menos um dos parentes com diagnóstico de câncer com idade inferior a 50 anos. Ou seja, preenchia os 
A Importância da Suspeição Clínica no Diagnóstico e

Tratamento do Câncer Colorretal Hereditário

Marcus Valadão e Cols. critérios de Amsterdam. Além disso, apresentava alguns dos critérios de Bethesda: Dois tumores relacionados à HNPCC, incluindo câncer colorretal metacrônico; câncer de cólon direito em idade inferior a 45 anos; presença de câncer colorretal associado a parente de primeiro grau com câncer colorretal diagnosticado em idade inferior a 50 anos. A presença de todos esses critérios levava a uma forte suspeita de se tratar de um caso de HNPCC, porém o padrão-ouro para o diagnóstico continua sendo o sequienciamento genético. Infelizmente, não é acessível a todos os centros, pois é um método de alto custo, o que inviabiliza sua utilização em larga escala. Mesmo que fosse realizado no presente caso, provavelmente não alteraria a conduta empregada, visto que a proposição de cirurgia profilática é problemática (pouca aceitação do paciente jovem em ser submetido à colectomia total profilática, principalmente pelas consequiências dessa cirurgia na qualidade de vida). Mesmo quando é feita a opção pela cirurgia profilática, existe ainda a discussão quanto à melhor abordagem a se propor, seja colectomia total ou proctocolectomia total, visto que a preservação do reto está relacionada a uma melhor qualidade de vida e menor morbidade operatória. ${ }^{24}$ No entanto, é possível o desenvolvimento de tumor metacrônico no reto remanescente, como no presente caso. Dessa forma, o papel da cirurgia profilática é discutível, visto que cerca de cerca de $60 \%$ dos pacientes não apresentariam tumor metacrônico. Quanto aos familiares que apresentassem mutações em genes de reparo (evidenciadas pelo sequienciamento ou pela pesquisa de MSI), porém sem neoplasia, estaríamos operando de forma preventiva cerca de $20 \%$ dos casos desnecessariamente, visto que a penetrância da mutação está em torno de $80 \%$ (nem todos que apresentam a mutação desenvolveriam o câncer colorretal), diferentemente dos casos de polipose adenomatosa familiar (PAF) onde a penetrância é de praticamente $100 \%$, além da expressão fenotípica da polipose que confirma a síndrome clinicamente. Apesar de se saber que o paciente em questão tinha uma chance alta de ser portador de HNPCC, a primeira cirurgia proposta foi de colectomia direita associada a acompanhamento colonoscópico rigoroso, pois tem sido descrito que a chance de desenvolvimento de câncer colorretal metacrônico é de mais de $40 \%$ em $10 \operatorname{anos}^{16}$. Apesar do conhecimento de que o desenvolvimento do câncer na HNPCC se dá de forma bem mais rápida que nos outros tipos, nesse caso em especial, houve uma evolução extremamente rápida do desenvolvimento do câncer de reto metacrônico (um ano), que já se apresentava em estádio avançado (T4). Essa mesma lesão levaria vários anos para atingir esse ponto caso se tratasse de CCR esporádico. Dessa forma, o seguimento rigoroso e a suspeição clínica foram decisivos para que o diagnóstico da lesão retal não tivesse sido mais retardado.

A presença da doença metacrônica de evolução rápida foi decisiva para que optássemos pela proctocolectomia total na segunda intervenção, tendo como base o racional de que toda mucosa colônica seria suscetível ao desenvolvimento de câncer nessa síndrome e que a chance de aparecimento de outros tumores seria extremamente alta.

Quanto à investigação dos familiares de primeiro grau, foram infrutíferas as tentativas de convencê-los da importância da realização de exames para detectar quais dos parentes seriam portadores da síndrome. Apesar de ter sido esclarecido aos familiares os riscos a que eles estavam sujeitos, eles não concordaram com a investigação, o que certamente se deve ao fato de os exames existentes serem bastante incômodos, dificultando sobremaneira sua aceitação por parte dos pacientes, principalmente se forem assintomáticos. A pesquisa de MSI, realizada em sangue periférico, não apresenta tal inconveniente e é capaz de detectar os portadores de instabilidade antes mesmo que desenvolvam quaisquer neoplasias ${ }^{17-18}$. No entanto, seu maior inconveniente é o custo elevado.

Quaisquer testes preditivos têm um grande potencial de gerar estresse psicológico em níveis capazes de atrapalhar a aderência dos pacientes a programas de tratamento e seguimento visando à sua própria saúde ${ }^{25}$. Apesar de a percepção de se estar "em risco" poder levar a um maior comportamento preventivo e de vigilância, níveis extremos de ansiedade e estresse podem levar a comportamentos de evitação que terão efeito oposto ao desejado. Além disso, uma grande parcela de indivíduos com história familiar de câncer recusa-se a ser investigada em virtude de haver sido mal informada quanto a seus riscos, freqüentemente, por profissionais de saúde com pouca experiência em testagem genética pré-sintomática ${ }^{26-}$ 27 , o que fala a favor da importância do aconselhamento genético pré-teste e pós-teste para quaisquer situações onde análise de mutações for realizada com fins de diagnóstico ou avaliação de risco. Por outro lado, a possibilidade de testagem genética para HNPCC abre margem a uma discussão ainda maior, acerca de qual 
Rev bras Coloproct Outubro/Dezembro, 2008
A Importância da Suspeição Clínica no Diagnóstico e Tratamento do Câncer Colorretal Hereditário Marcus Valadão e Cols.
Vol. 28 seria a conduta mais apropriada a se tomar com relação aos pacientes assintomáticos assim detectados. Como já mencionado acima, HNPCC têm penetrância incompleta (de 80\%). Dito de outra forma, isso significa que um em cada cinco pacientes portadores de mutações em genes de reparo jamais virá a desenvolver câncer algum (ao contrário do que ocorre com a PAF, onde a penetrância é de $100 \%$ ). Uma vez que não se pode determinar quais desses indivíduos manifestarão CCR, submeter toda essa população a cirur- gias profiláticas de grande porte é uma conduta aventada, porém absolutamente contraproducente, até porque o risco de neoplasias extracolônicas ainda permanecerá mesmo assim ${ }^{28-31}$. $\mathrm{O}$ avanço das pesquisas nesse campo poderá revelar quais fatores levam ao surgimento de câncer nesses pacientes, incluindo-se aí alelos modificadores, fatores epigenéticos, agentes ambientais, abrindo novas possibilidades no diagnóstico e manejo de síndromes de predisposição hereditária ao câncer, como HNPCC.

\begin{abstract}
In this article we report the case of a patient with Lynch syndrome (HNPCC) who developed metachronic rectal cancer in a short time interval after the primary tumor had been treated (right colon cancer). The objective of this case report is to point out the importance of clinical suspicion in the diagnosis of hereditary colorectal cancer and its therapeutics implications.
\end{abstract}

Key words: Colorectal hereditary cancer; diagnosis; treatment.

\section{REFERÊNCIAS}

1. Yu HJA, Lin KM, Ota DM, Lynch HT. Hereditary nonpolyposis colorectal cancer: preventive management. Cancer Treat Rev. 2003; 29(6):461-70.

2. Lynch HT, Shaw MW, Magnuson CW, Larsen AL, Krush AJ. Hereditary factors in cancer. Study of two large midwestern kindreds. Arch Intern Med. 1966; 117(2):206-12.

3. Lynch HT, de la Chapelle A. Genetic susceptibility to nonpolyposis colorectal cancer. J Med Genet. 1999; 36(11):80118.

4. Rousseau DL, Midis GP, Feig BW, et al. Cancer of the colon, rectum, and anus. In: Feig BW, Berger DH, Fuhrman GM, editors. The M.D. Anderson Surgical Oncology Handbook, $3^{\text {rd }}$ ed. Philadelphia: Lippincott Williams \& Wilkins; 2003.

5. Peltomäki P, Vasen HF. Mutations predisposing to hereditary nonpolyposis colorectal cancer: database and results of a collaborative study. The International Collaborative Group on Hereditary Nonpolyposis Colorectal Cancer. Gastroenterology. 1997; 113(4):1146-58.

6. Brose MS, Smyrk TC, Weber B, Lynch HT. Genetic predisposition to cancer. In: Holland JF, Frei EIII, Bast RC, Kufe DW, Pollock RE, Weichselbaum RR, editors. Cancer Medicine. $5^{\text {th }}$ ed. Canada: BC Decker; 2000.

7. Lynch HT, Lynch J. Lynch syndrome: genetics, natural history, genetic counseling, and prevention. J Clin Oncol. 2000; 18(21 Suppl):19S-31S.

8. Lynch HT, Lynch JF. Hereditary nonpolyposis colorectal cancer. Semin Surg Oncol. 2000; 18(4):305/13.

9. Vasen HF, Mecklin JP, Khan PM, Lynch HT. The International Collaborative Group on Hereditary Nonpolyposis Colorectal Cancer (GCI-CCHNP). Dis Colon Rectum. 1991; 34(5): 424-5.
10. Watson P, Lin KM, Rodrigues-Bigas MA, Smyrk T, Lemon S, Shashidharan M, Franklin B, Karr B, Thorson A, Lynch HT. Colorectal carcinoma survival among hereditary nonpolyposis colorectal carcinoma family members. Cancer. 1998; 83(2):25966.

11. Vasen HF, Watson P, Mecklin JP, Lynch HT. New clinical criteria for hereditary nonpolyposis colorectal cancer (, HNPCC, Lynch syndrome) proposed by the International Collaborative Group on HNPCC. Gastroenterology. 1999; 116(6):1453-6.

12. Boland CR, Thibodeau SN, Hamilton SR, Sidransky d, Eshleman JR, Burt RW, Meltzer, SJ, Rodriguez-Bigas MA, Fodde R Ranzani GN, Srivastava S. A National Cancer Institute workshop on microsatellite instability for cancer detection and familial predisposition: development of international criteria for the determination of microsatellite instability in colorectal cancer. Cancer Res v. 58, p. 52485257, 1998.

13. Rodriguez-Bigas MA., Boland CR, Hamilton SR, Henson DE, Jass JR, Khan PM, Lynch H, Perucho M, Smyrk T, Sobin L. A National Cancer Institute Workshop on Hereditary Nonpolyposis Colorectal Cancer Syndrome: meeting highlights and Bethesda guidelines. J Natl Cancer Inst. 1997; 89(23):175862.

14. Umar A, Boland CR, Terdiman JP, Syngal S, de la Chapelle A, Ruschoff J, Fishel R, Lindor NM, Burgart LJ, Hamelin R, Hamilton SR, Hiatt RA, Jass J, Lindblom A, Lynch HT, Peltomaki P, Ramsey SD, Rodriguez-Bigas MA, Vasen HF, Hawk ET, Barrett JC, Freedman AN, Srivastava S. Revised Bethesda guidelines for hereditary nonpolyposis colorectal cancer (Lynch syndrome) and microsatellite instability. J Natl Cancer Inst. 2004; 96(4):261-8. 
15. Valadão M, Castro LS. Câncer colorretal hereditário. Rev Col Bras Cir2007; 34: 193-200.

16. Rodriguez-Bigas M, Vasen HF, Pekka-Mecklin J, Myrhøj T, Rozen P, Bertario L, Järvinen HJ, Jass JR, Kunitomo K, Nomizu T, Driscoll DL. Rectal cancer risk in hereditary nonpolyposis colorectal cancer after abdominal colectomy. Ann Surg. 1997; 225(2):202-7.

17. Lipton LR, Johnson V, Cummings C, Fisher S, Risby P, Sadat AT, Cranston T, Izatt L, Sasieni P, Hodgson SV, Thomas HJ, Tomlinson IP. Refining the Amsterdam Criteria and Bethesda Guidelines: testing algorithms for the prediction of mismatch repair mutation status in the familial cancer clinic. J Clin Oncol. 2004; 22(24):4934-43.

18. Wüllenweber HP, Sutter C, Autschbach F, Willeke F, Kienle P, Benner A, Bahring J, Kadmon M, Herfarth C, von Knebe Doeberitz M, Gebert J . Evaluation of Bethesda guidelines in relation to microsatellite instability. Dis Colon Rectum 2001; 44(9):1281-9.

19. Southey MC, Jenkins MA, Mead L, Whitty J, Trivett M, Tesoriero AA, Smith LD, Jennings K, Grubb G, Royce SG, Walsh MD, Barker MA, Young JP, Jass JR, St John DJ, Macrae FA, Giles GG, Hopper JL. Use of molecular tumor characteristics to prioritize mismatch repair gene testing in early-onset colorectal cancer. J Clin Oncol. 2005; 23(27):652432. Epub 2005 Aug 22.

20. Vasen H, Mecklin JP, Watson P, Utsunomiya J, Bertario L, Lynch P, Svendsen LB, Cristofaro G, Muller H, Khan PM, et al. Surveillance in hereditary nonpolyposis colorectal cancer: an international cooperative study of 165 families. The International Collaborative Group on CCHNP. Dis Colon Rectum. 1993; 36(1):1-4.

21. Simmang C, Senagore P Lowry A, Hicks T, Burnstein M, Dentsman F, Fazio V, Glennon E, Hyman N, Kerner B, Kilkenny J, Moore R, Peters W, Ross T, Savoca P, Vernava A, Wong WD. Practice parameters for detection of colorectal neoplasms. The Standards Committee, the American Society of Colon and Rectal Surgeons. Dis Colon Rectum. 1999; 42(9):1123-9.

22. DeCosse JJ. Surgical prophylaxis of familial colon cancer: prevention of death from familial colorectal cancer. J Natl Cancer Inst Monogr. 1995; (17):31-2.
23. Instituto Nacional do Câncer; http://www.inca.gov.br, acessado em 10 junho 2008 às 18:00h.

24. Cutait R. Registros de Câncer Colorretal Hereditário. In: HNPCC - Câncer colorretal hereditário não-polipose. $1^{\mathrm{a}} \mathrm{ed}$., São Paulo, Ernesto Reichman, 2004.

25. Burke W, Peterson G, Lynch P, Botkin J, Daly M, Garber J, Khan MJ, McTiernan A, Offit K, Thomson E, Varricchio C. Recommendations for follow-up care of individuals with an inherited predisposition to cancer. I. Hereditary nonpolyposis colorectal cancer. Cancer Genetics Studies Consortium. JAMA. 1997; 277(11):915-9.

26. Lerman, C.; Rimer, B.K. Psychological impact of Cancer Screening In: Croyle, R.T. Psychological Impact of Screening for Disease Prevention and Detection. New York: Oxford University Press, 1995. p. 65-81.

27. Houtz, P.S.; Wojtkowiak, S.L.; Simmonds, M.A.; Weinberg, G.B.; Heitjan, D.F. Using a State Cancer Center Registry to Increase Screening Behaviors of Sisters and Daughters of Breast Cancer Patients. American Journal of Public Health, 81(3), 386-388, 1991.

28. Lynch HT, Krush AJ Cancer Family "G” Revisited: 18951970. Cancer, v. 27, p. 1505-1511, 1971.

29. Offit, K Clinical Cancer Genetics; Risk Counselling and Management. New York: Wiley-Liss, 1998.

30. Wijnen JT, Vasen HF, Khan PM, Zwinderman AH, van der Klift H, Mulder A, Tops C, Moller P, Fodde R. Clinical findings with implications for genetic testing in families with clustering of colorectal cancer. N Engl J Med. 1998; 339(8):5118.

31. Van den Bosch T, Vandendael A, Van Schoubroeck D, Wranz PA, Lombard CJ. Combining vaginal ultrasonography and office endometrial sampling in the diagnosis of endometrial disease in postmenopausal women. Obstet Gynecol. 1995; 85(3):345-52.

\section{Endereço para correspondência:}

MARCUS VALADÃO

Rua Paissandu, 385/302 - Flamengo 22210-080

Rio de Janeiro - RJ

E-mail: marcusvaladao@terra.com.br 